\title{
A late Mesozoic high plateau in eastern China: Evidence from basalt vesicular paleoaltimetry
}

\author{
XIA GuoQing $^{1 *}$, YI HaiSheng $^{1,2}$, ZHAO XiXi $^{3}$, GONG DaXing $^{1} \&$ JI ChangJun $^{1}$ \\ ${ }^{1}$ Institute of Sedimentary Geology, Chengdu University of Technology, Chengdu 610059, China; \\ ${ }^{2}$ State Key Laboratory of Oil/Gas Reservoir Geology and Exploitation, Chengdu 610059, China; \\ ${ }^{3}$ Department of Earth and Planetary Sciences, University of California, Santa Cruz, California 95064, USA
}

Received January 12, 2012; accepted March 2, 2012; published online May 15, 2012

\begin{abstract}
Eastern China is made of a number of large and small continental fragments throughout late Paleozoic and Mesozoic time, and is still the best natural laboratory for examining kinematic models of continent tectonics. The paleoelevation history of eastern China provides direct insight into the tectonic processes in China. Here we present basalt-vesicularity based estimates of the paleoaltimetry of the early Cretaceous basalts in northern East China, which indicate that the studied basalt units were at an elevation of more than 4 kilometers in late Mesozoic. Two vesicular basaltic rocks have been collected form bottom to top along the lava flow outcrop in eastern Inner Mongolia. After the digital precessing to the sample cross-sections, and taking advantage of the stereological conversion method to acquire the bubble size distributions, paleoelevation estimate was calculated for East China in the early Cretaceous. The results show that the elevation has been near $4700 \pm 750 \mathrm{~m}$ when the lava flows was cooling, implying that there were highland regions in the northern part of the East China Plateau during the early Cretaceous. Combined with other geological evidence, we conclude that there was a high plateau with elevation near $5000 \mathrm{~m}$ above sea level in Eastern China during the late Mesozoic. This ancient high plateau in eastern China was most likely formed by the collision of the north and south China blocks.
\end{abstract}

early Cretaceous, east China Plateau, vesicular-basalt, paleoaltimetry, north and south China collision

Citation: $\quad$ Xia G Q, Yi H S, Zhao X X, et al. A late Mesozoic high plateau in eastern China: Evidence from basalt vesicular paleoaltimetry. Chin Sci Bull, 2012, 57: 2767-2777, doi: 10.1007/s11434-012-5169-0

For the last three decades, numerous geological and paleomagnetic studies have shown that China was assembled from a number of large and small continental fragments throughout late Paleozoic and Mesozoic time. The tectonic configuration of eastern China is dominated by the North China Block (NCB) in the north and the South China Blocks (SCB) in the south (Figure 1(a)). The collision between the North and South China Blocks has played a central role in shaping the eastern Asian continent. One early tectonic model of the collision, based on paleomagnetic data and geologic evidence [1], envisions that in the latest Permian and Early Triassic the North and South China Blocks started colliding near the eastern end of what is now the

\footnotetext{
*Corresponding author (email: xiaguoqing06@163.com)
}

Qinling mountain belt (Figure 1(a)). After the initial contact in the east, suturing migrated progressively westward during the Early Mesozoic as the two blocks scissored together, eliminated the intervening marginal sea, and completed docking by Late Jurassic time.

Since the main collision and suturing between the NCB and SCB, however, there has been significant tectonic activity in the region. To the north, the scissors-like closure of the United China Block (NCB, SCB, and Mongolia) and Siberia did not end until Juro-Cretaceous time [2,3]. To the east, the subduction of the Kula plate beneath the Asian continental margin and the opening of the Bohai sea began in the Juro-Cretaceous [4]. To the west, the collision between India and Asia commerced in the Eocene, and continued to the present [5]. Besides causing large-scale intracontinental 


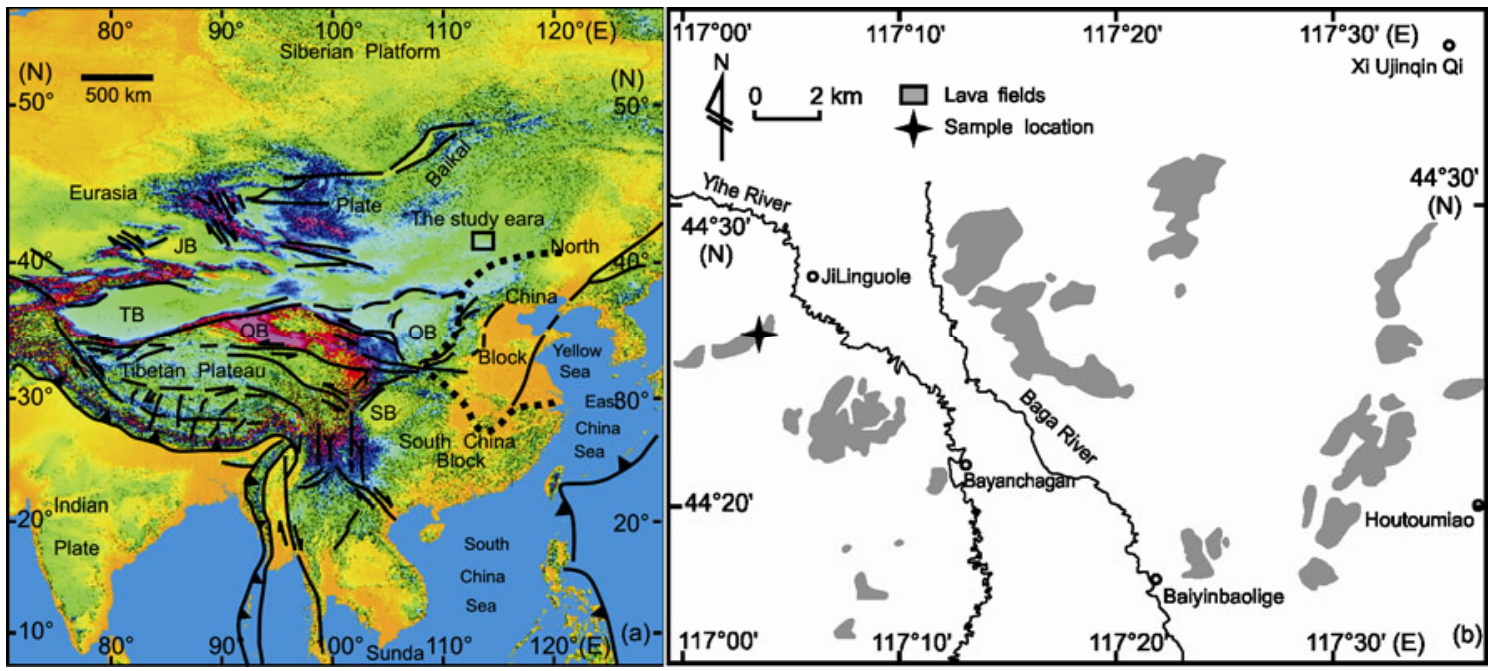

Figure 1 (a) Sampling localities in Inner Mongolia; (b) details of lava fields of the early Cretaceous Daote Nuoer Formation (shaded areas). Square box in (a) shows the location of (b). The dashed lines in (a) are the ancient plateau range delineated by Zhang et al. [6]. Our sampling location is $200 \mathrm{~km}$ north of the boundary.

deformation and the most extensive region of the elevated topography in the world, the forceful collision and uplift of India and Asia appear also to be responsible for the today's topographic trend of China, with high plateaus in the west and low lands towards the east.

Several recent studies, however, suggested that parts of eastern China in late Mesozoic were probably in a region of high plateau, with its scale and elevation similar to that of the today's Qinghai-Tibet Plateau [6]. Geologic records also suggest that east Asia reversed its topography from westtitling in late Mesozoic to today's east-tilting, an event that has exerted profound influence on paleoclimate and continent-ocean interactions [7]. Interestingly, abnormal largescale magmatism also occurred in eastern China in late Mesozoic. Many acidic volcanics and irruptive rocks among them are geochemically analogous to adakites. These rocks are characterized by HREE depletion and no obvious negative Eu anomaly, low Y contents but high $\mathrm{La} / \mathrm{Yb}$ and $\mathrm{Sr} / \mathrm{Y}$ ratios [6]. Compared with the typical adakites in the Pacific Ocean, these rocks are enriched in $\mathrm{K}_{2} \mathrm{O}\left(\mathrm{Na}_{2} \mathrm{O} / \mathrm{K}_{2} \mathrm{O}=0.9\right.$ $1.3)$, with high contents of $\mathrm{Sr}(0.705-0.709)$, and generally with $€ \mathrm{Nd}<0$. These geochemical signatures indicate that the adakite (C-type adakite) is derived from a deep source and is a product of partial melting of the lower-crust granulite or femic amphibolite in a thickened crust $(>50 \mathrm{~km})$ resulted from underplating of basaltic magma [6]. If the thicked crust corresponding to an elevated region, based on the principle of isostatics, then the late Jurassic to early Cretaceous aged C-type adakite volcanism may indicate the formation of a high plateau in Eastern China. This hypothesis has been favored by several constraints provided by paleogeographic, paleontologic, and paleoclimatic studies [8-12]. On the other hand, there are conflicting views on this Paleoplateau of eastern China, mainly from the lack of convincing evidence to show whether these igneous rocks which have high $\mathrm{Sr}$ contents but low $\mathrm{Yb}$ could be called adakites [13-15].

Measuring the paleoelevation of high plateaux is critical to understanding their geodynamic evolution and tectonic process. Over the past decades, several techniques have been developed for measuring rock uplift and exhumation, such as tectonogeomorphic studies of fluvial systems and drainage basins [16], thermochronologic studies like those using apatite fission track dating [17], or (U-Th)/He thermochronology [18,19], stratigraphic and chronologic studies of erosional sediments and their accumulation rates [20], enthalpy or paleo- $\mathrm{pCO}_{2}$ estimates based on paleoflora [21-24], and oxygen and hydrogen isotope studies of meteoric water and its proxies [25-29].

In recent years, a direct technique was developed for measuring paleoelevation via paleoatmospheric pressure on the basis of the vesicularity of basaltic lava flows [30-33]. This method is based on the difference in internal pressure between bubbles at the top and base of lava flows. At the top of the flow, pressure is atmospheric, while at the bottom of the flow, pressure is atmospheric plus the hydrostatic pressure of the overlying flow. The modal size of the vesicle (bubble) population is larger at the top than at the bottom.

Thus,

$$
P=\rho g H /(\alpha-1)
$$

where $P$ is atmospheric pressure, $\rho$ is the density of the lava, $g$ is the acceleration of gravity, $H$ is the thickness of the flow, and $\alpha=V_{\mathrm{T}} / V_{\mathrm{B}}, V_{\mathrm{T}}$ and $V_{\mathrm{B}}$ are modal vesicle volumes between the top and base. Because lava thickness can be measured in the field, and the vesicle sizes can be measured in the lab, a simple relation can be solved for atmospheric pressure, and using the standard atmosphere, elevation can be determined. Sahagian and colleagues have successfully 
tested this method with recent flows on the slopes of Mauna Loa, Hawaii, with an error of $\pm 400 \mathrm{~m}$ [31].

If indeed there existed a high plateau in eastern China, it would have no doubly not only affected the landform environment and the paleogeography of eastern China in late Mesozoic, but also influenced the paleoclimate of East Asia and by enlarge the world at that time. Paleoelevation estimation for this possible ancient plateau in eastern China has been an important scientific subject, around which there are considerable discussions and disputes. The widely different views have arisen because each investigation has been based on a particular line of evidence which is indirect proxy for paleoelevation, such as adakites, palaeoclimate and palaeobiocoenosis, but lack of direct study for elevation estimate, such as basalt vesicularity. Fortunately, Mesozoic vesicular basaltic rocks are extensively distributed in Eastern China which could potentially provide estimates for paleoelevation and range of the ancient Eastern China Plateau. In this paper we present results from the first study of early Cretaceous vesicular basaltic rocks from in Ji Linguole town, Inner Mongolia, examine the question of the existence of the ancient high Plateau in eastern China, and discuss the possible cause for the formation of this high plateau.

\section{Sampling site and methods}

An appropriate vesicular basaltic rock sample and reasonable vesicular statistical method are the keys paleoelevation determination using with basaltic vesicularity method. For this study, basaltic samples were collected from a quarry located $5 \mathrm{~km}$ to the south of Jilin Guole town in Xi Ujinqin Qi $\left(44^{\circ} 25^{\prime} 28^{\prime \prime} \mathrm{N}, 117^{\circ} 04^{\prime} 38^{\prime \prime} \mathrm{E}\right.$, altitude $\left.1074 \mathrm{~m}\right)$ of Inner Mongolia (Figure 1(b)). According to the regional geological survey, these lavas belong to the Daote Nuoer Formation with well defined contact relationship in the field. The age of the Daote Nuoer Formation is reported as late Jurassic. However, recent studies by Chen et al. [34] obtained isotope ages for the rhyolites of the Chaganuoer Formation which underlies the Daote Nuoer Formation, and the basaltic andesite in the Bulagenhada Formation which overlies the Daote Nuoer Formation in the adjacent area. According to Chen et al., the age of the Daote Nuoer Formation should be between 142 and $129 \mathrm{Ma}$, which is in the Early Cretaceous.

At the sampling site, lava flows could be identified by a brick red or purple red oxidation roof on the top of each flow (Figure 2(a)). We targeted thick flows (at least $3 \mathrm{~m}$ in thickness) and selected flows within it the size of bubbles
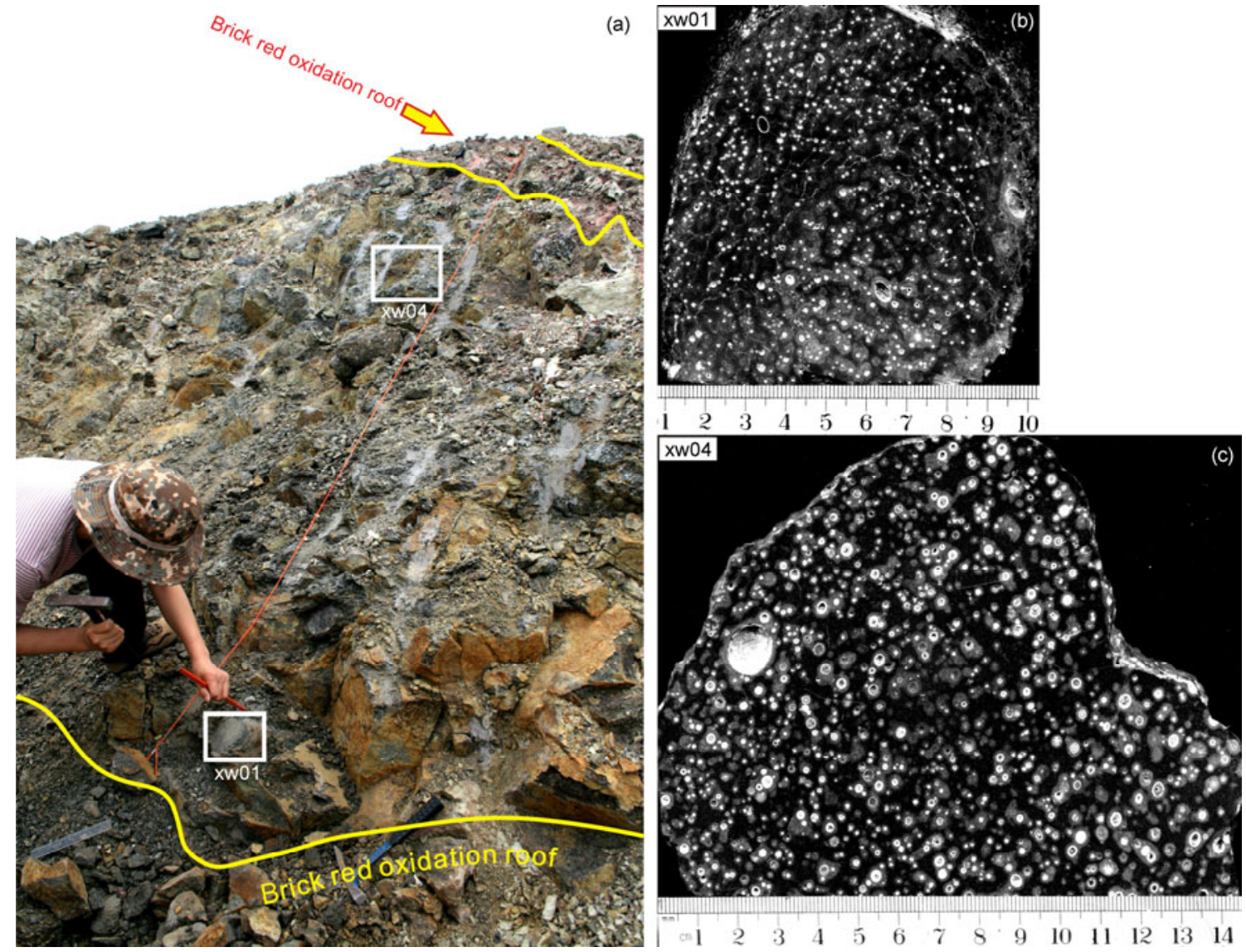

Figure 2 The outcrop of vesicular basalt (a) and cross-sections of Dao Tenuoer Formation vesicular basalt samples (b), (c) in Ji Linguole, Xi Ujinqin Qi, Inner Mongolia (the smallest calibration of ruler: $\mathrm{mm}$ ). Because samples were collected from a newly explored quarry, the outcrop is very messy. Even so, the eruption rhythm of lava flow is very clear. 
must have clearly differentiation in vertical sense and have not been influenced by the pulling and dragging of the lava flow. To avoid the influence of external atmospheric pressure, the rocks inside the red roof were not collected for this study.

The vesicular basaltic rocks samples have been collected form bottom to top along the lava flow outcrop. All the samples have been collected from the same eruption, and consist of purple gray basalts, with many vesicular, mainly consist of plagioclase, olivine and some vitreous composition. The phanerocrysts of plagioclase are board strips, often with symmetric twin, approximately $0.15-0.4 \mathrm{~mm}$ long, content of about $40 \%$. Olivines are fine automorphic crystals, grain diameter about $0.05-0.15 \mathrm{~mm}$, content of about $10 \%$. Vitreous are turbid and not transparent, without microcrystal. Note our sampling location is outside of the inferred ancient eastern plateau by Zhang et al. (see the dotted lines in Figure 1(a)).

Determining the top and bottom along the transaction of the samples is the first step of the lab work, then grinding and buffing with randomness. We selected two samples (xw01 and xw04), which are uninfluenced by the pulling and dragging and nearly null coalescence, for vesicular statistics (Figure 2(b),(c)).

It is important to exactly measure modal vesicle size for measuring paleoelevation through paleoatmospheric pressure. There are three main methods to estimate the distribution patterns of vesicular basaltic in 3 dimensional space [35]. The first method is injecting hand samples with plastic monomer which subsequently polymerized, and then dis- solving away the basalt, leaving plastic casts of vesicles for measurement and counting [36,37]. The second and more efficient technique is to determine vesicle size distributions from 2D cross-sections of hand samples [38,39]. The most accurate method for measuring bubble size distributions is the third, a High Resolution X-Ray Computed Tomography (HRXCT) method [40], which conducts high resolution 3D scanning of the basalt with X-Ray, and then modeling and counting.

This paper uses the second method, with the following operation procedures: (1) cut samples into thin sections; (2) examine the polished surfaces (and a scale) with a scanner at $600 \mathrm{dpi}$; (3) use two image processing tools (Adobe Photoshop and Image J) to optimize the pictures, including the resolution improvement, de-noising, filtering, gray image segmentation and the vesicular area measurement; (4) calculate the vesicle sizes through pixel conversion; and (5) convert the bubble size distributions form 2D area to 3D volume based on the principles and applications of stereology. Finally, we estimate paleoelevation according to eq. (1) above and the method described by Sahagian et al. [33].

\section{Reconstruction of size distribution of the vesicles and paleoelevation resutls}

Figure 2(b), (c) shows scanning images of samples used for this study. A total of 564 and 710 stomas are detected in the cross-sections of sample xw01 and sample xw04, respectively. Figure 3 shows the frequency distribution of observed
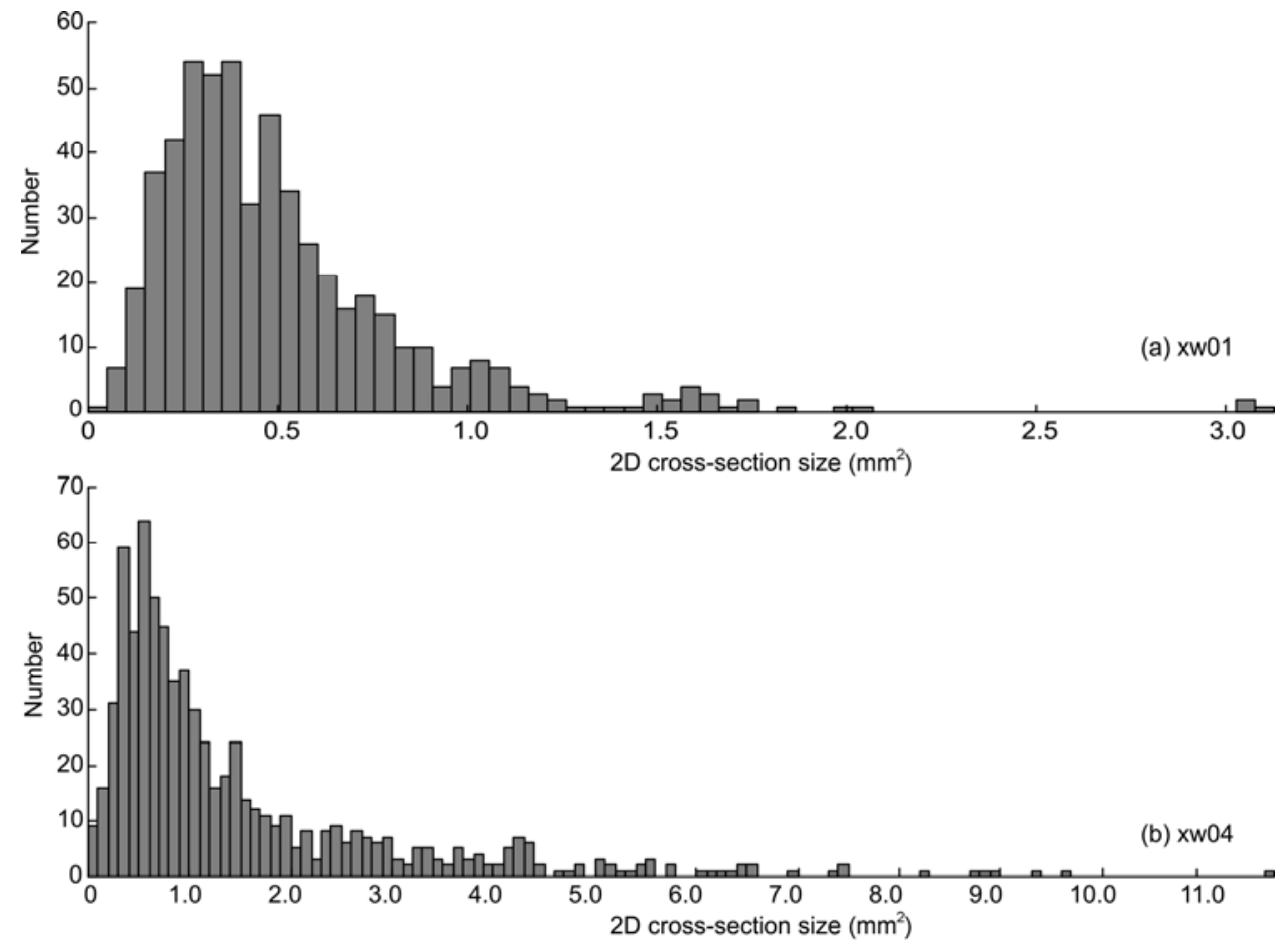

Figure 3 Frequency distribution of observed 2D cross-section sizes. 
2D cross-section sizes. The area of observed 2D cross-section on sample $\mathrm{xw} 01$ ranges from 0 to $2 \mathrm{~mm}^{2}$, and for sample $\mathrm{xw} 04,0$ to $7 \mathrm{~mm}^{2}$. Several stomas areas, accounting for less than $1 \%$, are relatively scattered, which are obviously bigger than the average area of all stomas on the cross-section (even several times bigger than the average area). These areas could have been merged by several normal stomas and were not used in this study to ensure the accuracy of counting.

When a random plane cuts a distribution of particles, it does not intersect each through its center, but rather, the set of intersections can be divided into a probability distribution according to cross-section size, this distribution does not represent that of the $3 \mathrm{D}$ particles, but is normally described by a finite number of discrete size classes [39]. So we must use a stereological 2D to 3D conversion techniques $[38,40]$.

Many workers have used section size of rounds in 2D to calculate volume of the spheres in 3D $[38,41,42]$. The sterological approach can be stated below. Let's assume $r$ is cross-section radius, $R$ is the sphere radius, $N_{V}$ is the number density of the largest particle size class in $3 \mathrm{D}$ volume, and $N_{A}$ is the number density of observed largest 2D cross-section class. If there is a bubble within $r$ radius, its number density can be calculated as

$$
N_{A}(r)=2 \int_{R=r}^{R_{\max }} N_{V}(R) \frac{r}{\sqrt{R^{2}-r_{2}}} \mathrm{~d} R,
$$

$N_{V}(R)$ is the number density of the particle size class within $R$ radius in 3D volume [42].

If we put the rounds (obtained from the cross-section) into groups according to their sizes, such as $n$ groups with the same group interval $(\Delta)$, then we can get the size range of the $j$ group rounds through $(j-1) \Delta-j \Delta$, and, its number density at cross-section is

$$
N_{A}(j)=\int_{j-1 \Delta}^{j \Delta} \int_{r}^{R_{\max }} \frac{2 r N_{V}(R)}{\sqrt{R^{2}-r^{2}}} \mathrm{~d} R \mathrm{~d} r .
$$

Because $R_{\max }=r_{\max }=j \Delta$, and only if $R \geqslant r$, the rounds could be obtained from the cross-section. Thus, we have

$$
\begin{aligned}
N_{A}(j) & =\int_{(j-1) \Delta}^{j \Delta} \int_{(j-1) \Delta}^{R} \frac{2 r N_{V}(R)}{\sqrt{R^{2}-r^{2}}} \mathrm{~d} r \mathrm{~d} R \\
& +\int_{j \Delta}^{n \Delta} \int_{(j-1) \Delta}^{j \Delta} \frac{2 r N_{V}(R)}{\sqrt{R^{2}-r^{2}}} \mathrm{~d} r \mathrm{~d} R \\
& =\int_{(j-1) \Delta}^{j \Delta} 2 \sqrt{R^{2}-(j-1)^{2} \cdot \Delta^{2}} \cdot N_{V}(R) \mathrm{d} R \\
& +\int_{j \Delta}^{n \Delta} 2\left[\sqrt{R^{2}-(j-1)^{2} \Delta^{2}}-\sqrt{R^{2}-j^{2} \Delta^{2}}\right] \cdot N_{V}(R) \mathrm{d} R .
\end{aligned}
$$

If we change the rounds with bubbles for grouping, $n$ groups, $\Delta$ is group interval, $(i-1) \Delta-\Delta$ is the size range of the $i$ group bubble, and only if $i \geqslant j$, the $j$ group cross-section could be obtained from the bubbles, then, a generalized form of the above formulation can be written as

$$
\begin{aligned}
N_{A}(j)= & \int_{(j-1) \Delta}^{j \Delta} 2 \sqrt{R^{2}-(j-1)^{2} \Delta^{2}} N_{V}(R) \mathrm{d} R \\
& +\sum_{i=j+1}^{n} \int_{(i-1) \Delta}^{j \Delta} 2\left[\sqrt{R^{2}-(j-1)^{2} \Delta^{2}}-\sqrt{R^{2}-j^{2} \Delta^{2}}\right] \\
& \times N_{V}(R) \mathrm{d} R,
\end{aligned}
$$

i.e.

$$
\begin{aligned}
N_{A}(j)= & 2 \sqrt{R_{(i=j)}^{2}-(j-1)^{2} \Delta^{2}} \int_{(j-1) \Delta}^{j \Delta} N_{V} \mathrm{~d} R \\
& +\sum_{i=j+1}^{n} 2\left[\sqrt{R_{i}^{2}-(j-1)^{2} \Delta^{2}}-\sqrt{R_{i}^{2}-(j-1)^{2} \Delta^{2}}\right] \\
& \times \int_{(i-1) \Delta}^{j \Delta} N_{V}(R) \mathrm{d} R .
\end{aligned}
$$

Because $\int_{(i-1) \Delta}^{j \Delta} N_{V} \mathrm{~d} R$ is the number density of the bubble size class in some volume of the $i$ group $\left(N_{V}(i)\right)$, so,

$$
N_{A}(j)=2 \Delta \sum_{i=j}^{n} k_{j i} N_{V}(i)
$$

in this formula:

$$
\begin{gathered}
k_{j i}=\frac{1}{\Delta} \sqrt{R_{(i=j)}^{2}-(j-1)^{2} \Delta^{2}} \quad(i=j), \\
k_{j i}=\frac{1}{\Delta}\left[\sqrt{R_{i}^{2}-(j-1)^{2} \Delta^{2}}-\sqrt{\mathrm{R}_{i}^{2}-j^{2} \Delta^{2}}\right] \quad(i>j) .
\end{gathered}
$$

The $k_{j i}$ could be calculated directly once the method of grouping and the group interval have beendetermined, then through back eq. (7), the size distribution in 3D of the bubbles $\left(N_{V}(R)\right)$ can be obtained via

$$
N_{V}(i)=\frac{1}{2 \Delta} \sum_{j=i}^{n} a_{i j} N_{A}(j),
$$

where $a_{i j}$ is the inverse matrix of $k_{j i}$.

According to the above methods, we have reconstructed bubble size distribution of the two samples (xw01, xw04). Firstly, we selected available area data which we obtained from the cross-sections, eliminated the discrete data that were obviously not harmonious. We then converted the available data to section round radius. Adopting GoldsmithCruz-Orive principle [43], we divided all the bubbles and section rounds into 15 groups with radius as standard, group interval $\Delta=R_{\mathrm{MAX}} / 15=r_{\max } / 15$. The radius size range of the cross-section rounds could be represented as $(j-1) \Delta-j \Delta$, and $(i-1) \Delta-i \Delta$ (size range of the bubbles). Take the average size as a nominal size in each group, i.e. nominal radius size of the $j$ group is $(j-1 / 2) \Delta,(i-1 / 2) \Delta$ the bubbles. Thus, the value of the coefficient $k_{j i}$ obtained is 


$$
\begin{gathered}
k_{j i}=\sqrt{\left(i-\frac{1}{2}\right)^{2}-(j-1)^{2}}=\sqrt{i-\frac{3}{4}} \quad(i=j), \\
k_{j i}=\sqrt{\left(i-\frac{1}{2}\right)^{2}-(j-1)^{2}}-\sqrt{\left(i-\frac{1}{2}\right)^{2}-j^{2}} \quad(i>j) .
\end{gathered}
$$

Results are listed as conversion coefficients $\left(k_{j i}\right.$ and $\left.a_{i j}\right)$ in Tables 1 and 2. Table 3 shows the number density of the largest bubble size class in $3 \mathrm{D}$ volume $N_{V}(i)$, which is calculated from the number density of observed largest 2D cross-section rounds $N_{A}(j)$.

We applied our stereological analysis to obtain the 3D size distribution. The analytical results are shown in Figure 4. As shown in Figure 4, the quantity probability density peak of the round radius that direct statistics in 2D crosssection is smaller than the bubble radius probability density peak from 3D reconstruction. In addition, bubbles size distribution of the two samples is the single-peak type of normal distribution, indicating that the lava flows only go through one time physallization and secondary bubble effect is week. Thus, the peak represents the standard bubble size and the samples used for this study are suitable for the basalt vesicles paleoelevation method.

The results of our stereological analysis indicated that the radius of modal bubble sizes of sample xw01 and xw04 are 0.44 and $0.49 \mathrm{~mm}$. In order to get the density of the sample, experiments were carried out in Institute of Multipurpose Utilization of Mineral Resources, Chinese Academy of Geological Sciences. The true density for the basalt is $2.5433 \times$ $10^{3} \mathrm{~kg} / \mathrm{m}^{3}$. After stratum thickness correction which is based on field attitude measurement, the distance from center of the two samples (xw01, xw04) to the top of the lava flows are, $243.38 \mathrm{~cm}$ and $115.33 \mathrm{~cm}$, respectively. Then, we can get that paleopressure at emplacement was 49300 pa by using eq. (1), If we assume sea level pressure and lapse rate have not changed significantly since Mesozoic, then the paleoelevation is deduced to be $4700 \mathrm{~m}$ in early Cretaceous when Dao Tenuoer Formation basalt was emplaced in Ji Linguole, Xi Ujinqin Qi, Inner Mongolia.

\section{Error analysis}

There is error introduced in any observational scheme. Vesicular basalt paleoatimetery is also no exception. Due to the nature of determining paleoelevations based on the vesicle size distributions in basaltic lavas, there are three error sources within the procedure: measurement of vesicle sizes, hydrostatic pressure at the base of lava flow and sea level pressure at the time of eruption [35], as we discuss below.

\subsection{Measurement of vesicle sizes}

In our analysis, vesicle size distributions come from 2D cross-sections of hand samples, which were converted to 3D using stereology. As a result, this error can be calculated on the basis of measurement errors of the size of vesicles and conversion errors from $2 \mathrm{D}$ to $3 \mathrm{D}$. The measuring errors were mainly caused by image grabber, quantization and optical system. From all accounts, this will lead to approximately error of $2 \%$, and corresponding to $\pm 210 \mathrm{~m}$ in elevation uncertainty. However, with effective method of measurement, this source of error should be reduced.

\begin{tabular}{|c|c|c|c|c|c|c|c|c|c|c|c|c|c|c|c|}
\hline \multirow{2}{*}{$\begin{array}{c}\text { Group } \\
\text { interval of } \\
\text { rounds }(j)\end{array}$} & \multicolumn{15}{|c|}{ Size range of bubbles $(i)$} \\
\hline & $N_{V(1)}$ & $N_{V(2)}$ & $N_{V(3)}$ & $N_{V(4)}$ & $N_{V(5)}$ & $N_{V(6)}$ & $N_{V(7)}$ & $N_{V(8)}$ & $N_{V(9)}$ & $N_{V(10)}$ & $N_{V(11)}$ & $N_{V(12)}$ & $N_{V(13)}$ & $N_{V(14)}$ & $N_{V(15)}$ \\
\hline$N_{A(1)}$ & 0.5000 & 0.3820 & 0.2087 & 0.1459 & 0.1125 & 0.0917 & 0.0774 & 0.0670 & 0.0590 & 0.0528 & 0.0477 & 0.0436 & 0.0401 & 0.0371 & 0.0345 \\
\hline$N_{A(2)}$ & & 1.1180 & 0.7913 & 0.4818 & 0.3564 & 0.2849 & 0.2380 & 0.2046 & 0.1796 & 0.1601 & 0.1445 & 0.1317 & 0.1210 & 0.1119 & 0.1041 \\
\hline$N_{A(3)}$ & & & 1.5000 & 1.0695 & 0.6770 & 0.5137 & 0.4184 & 0.3546 & 0.3084 & 0.2732 & 0.2455 & 0.2229 & 0.2043 & 0.1886 & 0.1751 \\
\hline$N_{A(4)}$ & & & & 1.8028 & 1.2925 & 0.8349 & 0.6428 & 0.5296 & 0.4530 & 0.3970 & 0.3541 & 0.3199 & 0.2919 & 0.2686 & 0.2489 \\
\hline$N_{A(5)}$ & & & & & 2.0616 & 1.4836 & 0.9702 & 0.7541 & 0.6261 & 0.5391 & 0.4752 & 0.4258 & 0.3863 & 0.3539 & 0.3267 \\
\hline$N_{A(6)}$ & & & & & & 2.2913 & 1.6533 & 1.0902 & 0.8531 & 0.7123 & 0.6162 & 0.5454 & 0.4906 & 0.4465 & 0.4103 \\
\hline$N_{A(7)}$ & & & & & & & 2.5000 & 1.8074 & 1.1990 & 0.9428 & 0.7906 & 0.6866 & 0.6097 & 0.5500 & 0.5020 \\
\hline$N_{A(8)}$ & & & & & & & & 2.6926 & 1.9495 & 1.2991 & 1.0255 & 0.8628 & 0.7515 & 0.6691 & 0.6050 \\
\hline$N_{A(9)}$ & & & & & & & & & 2.8723 & 2.0821 & 1.3924 & 1.1024 & 0.9300 & 0.8120 & 0.7246 \\
\hline$N_{A(10)}$ & & & & & & & & & & 3.0414 & 2.2068 & 1.4800 & 1.1747 & 0.9931 & 0.8688 \\
\hline$N_{A(11)}$ & & & & & & & & & & & 3.2016 & 2.3248 & 1.5628 & 1.2429 & 1.0528 \\
\hline$N_{A(12)}$ & & & & & & & & & & & & 3.3541 & 2.4372 & 1.6416 & 1.3078 \\
\hline$N_{A(13)}$ & & & & & & & & & & & & & 3.5000 & 2.5446 & 1.7168 \\
\hline$N_{A(14)}$ & & & & & & & & & & & & & & 3.6401 & 2.6477 \\
\hline$N_{A(15)}$ & & & & & & & & & & & & & & & 3.7749 \\
\hline
\end{tabular}

Table 1 Goldsmith-Cruz-Orive conversion coefficients $\left(k_{i j}, n=15\right)$ 


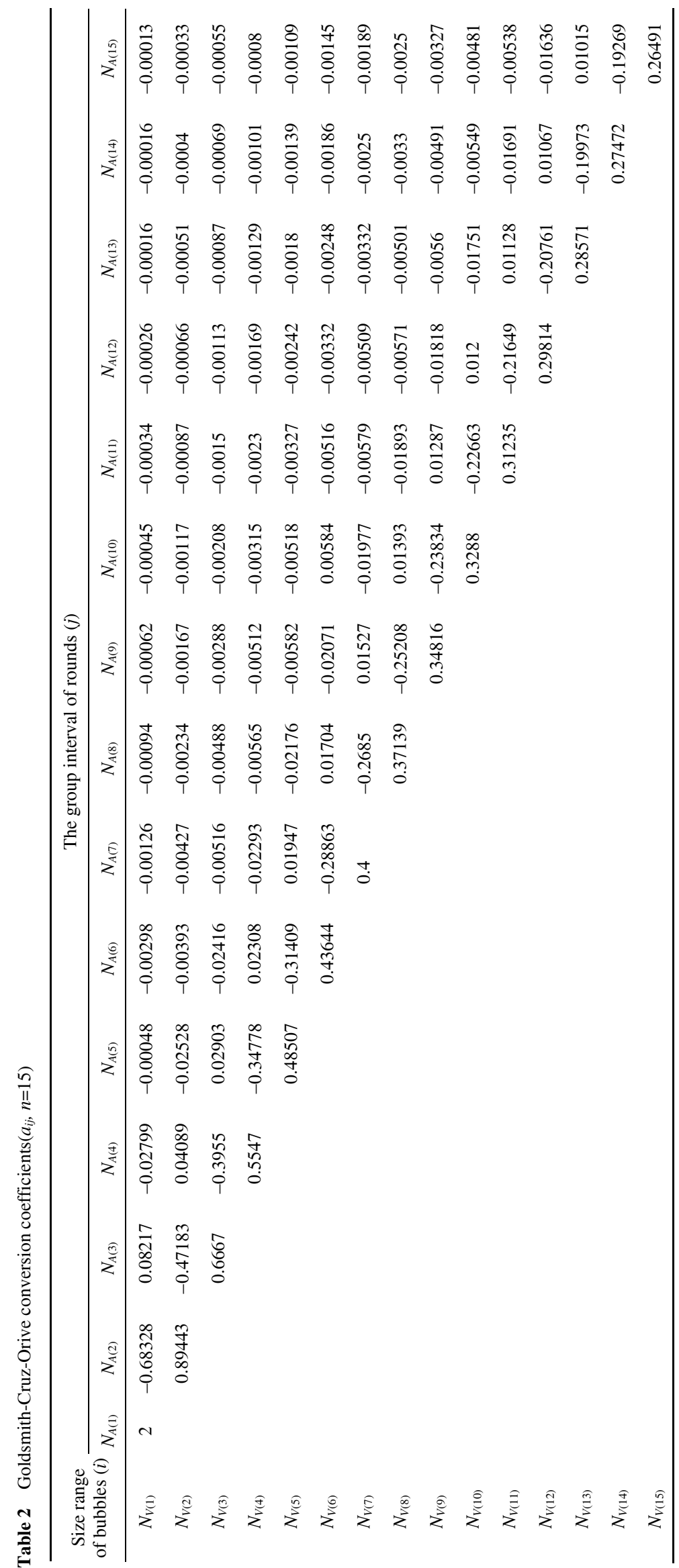




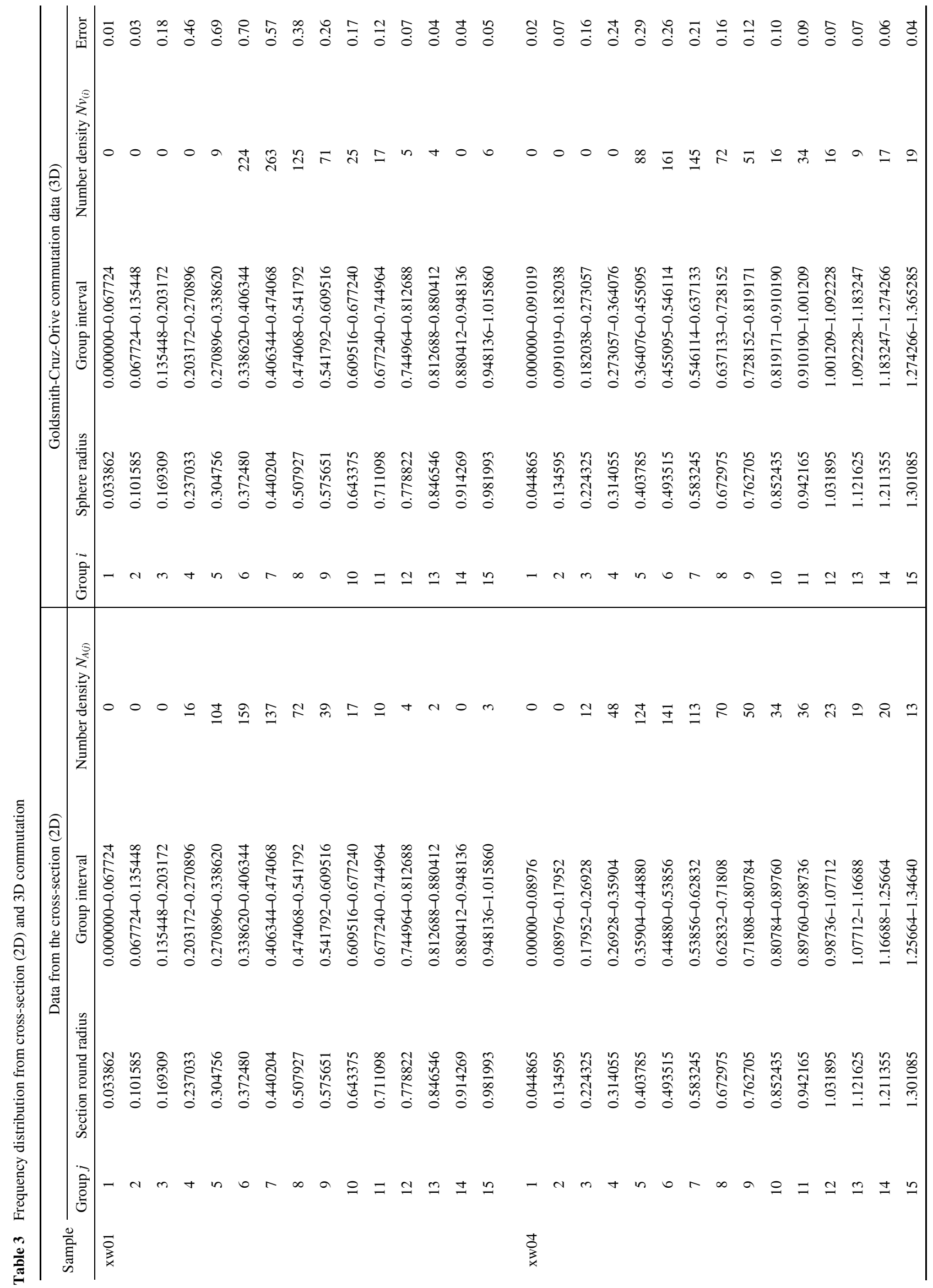



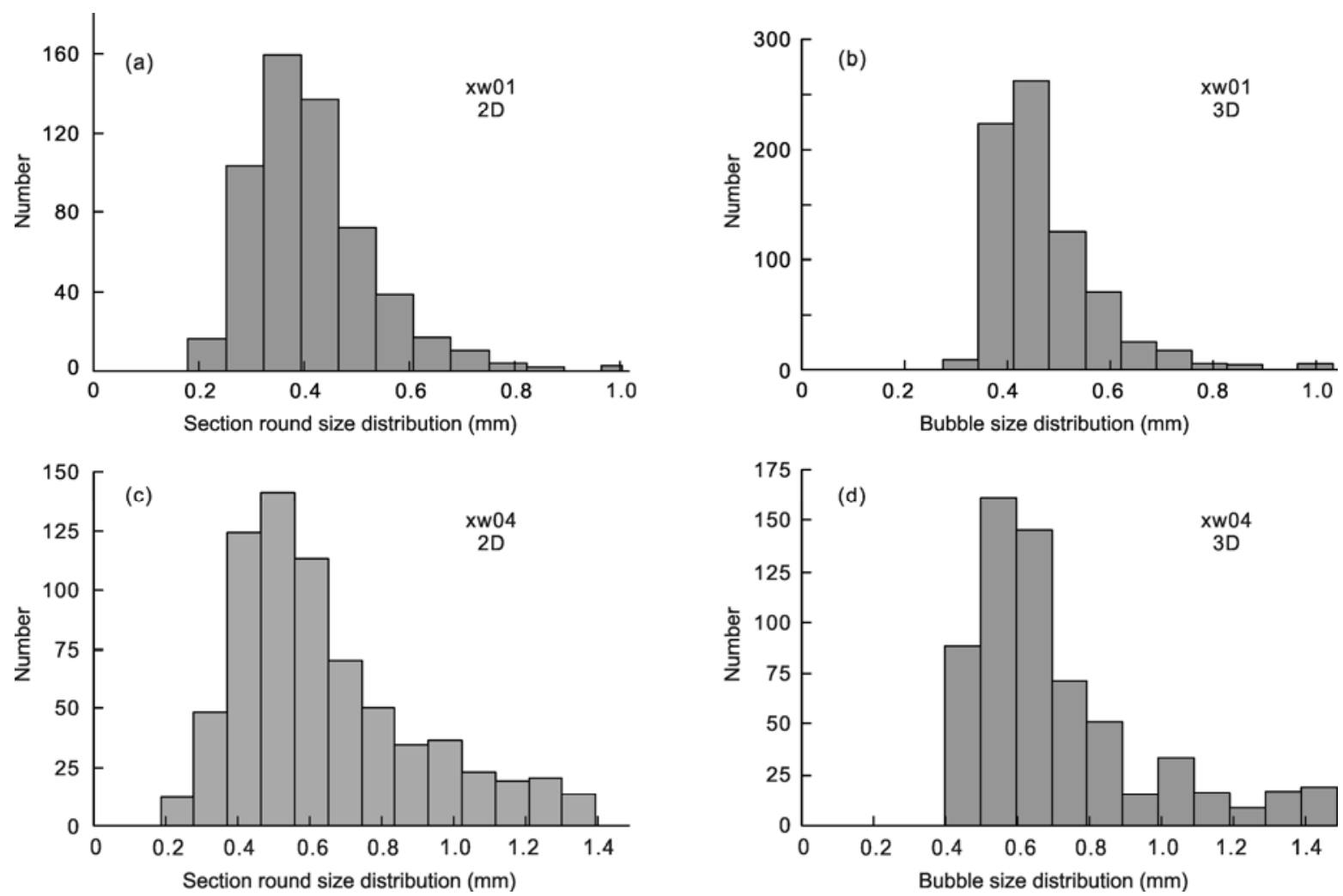

Figure 4 Histogram of frequency distribution from cross-section (2D) and derived 3D frequency distribution.

Another possible kind of error is caused by stereoscopic transformation. In our calculations, the transformation formulas is eq. (9), so that

$$
\sigma^{2}\left[N_{V}(i)\right]=\frac{1}{4 \Delta^{2}} \sum_{j=i}^{n}\left(a_{i j}\right)^{2} \sigma^{2}\left[N_{A}(j)\right] .
$$

Because

$$
N_{A}(j)=\frac{N(j)}{A_{T}},
$$

where $N(j)$ is the cross section numbers of the $j$ group, and $A_{T}$ is the totally tested area. Then we can obtain

$$
\sigma^{2}\left[N_{A}(j)\right]=\frac{\sigma^{2}[N(j)]}{A_{T}^{2}},
$$

where $N(j)$ is commonly subjected to Poisson probability, therefore,

$$
\sigma^{2}\left[N_{A}(j)\right]=\overline{N_{A}(j)} .
$$

Then, $\quad \sigma^{2}\left[N_{A}(j)\right]=\frac{\overline{N(j)}}{A_{T}^{2}}=\frac{N_{A}(j)}{A_{T}}$.

So, $\sigma\left[N_{V}(i)\right]$ can be found by integrating eq. (11), so that

$$
\sigma\left[N_{V}(i)\right]=\frac{1}{2 A_{T} \Delta} \sum_{j=i}^{n} a_{i j} \sqrt{N(j)}
$$

Table 3 shows the error of each group, their sum is the experiment transformation error of the samples, i.e. $3.77 \%$ for sample xw01, $1.96 \%$ for sample xw04. Accordingly, the final error of paleoelevation is $\pm 620 \mathrm{~m}$.

Error sources caused by hydrostatic pressure at the base of lava flow come from both density measurements and potential error resulting from unrecognized minor inflation or deflation after solidification of upper and lower parts of the flow. Generally, each centimeter of measurement error of inflation/deflation would lead to an error of $\pm 33 \mathrm{~m}$ in elevation, we assume an error term to account for $10 \mathrm{~cm}$ of inflation/deflation between samples xw01 and xw04. This $10 \mathrm{~cm}$ error assumption, which is admittably very big, can lead an elevation uncertainty of $\pm 330 \mathrm{~m}$ for a typical $3 \mathrm{~m}$ flow.

\subsection{Sea level pressure at the time of eruption}

Error sources caused by sea level pressure at the time of eruption are due to changing weather conditions. Typically, the time scale of these variations is no longer than several days for synoptic systems. Taking a conservative approach, variations in barometric pressure (due to weather) at the time of eruption will lead to an uncertainty of about $\pm 150 \mathrm{~m}$ for a given flow [35]. Of course, this kind of circumstance should exclude a hurricane or other very low pressure system.

Using the larger errors above, the total error from the various contributions is thus estimated as 
$\sqrt{210^{2}+620^{2}+330^{2}+150^{2}}$, or about $\pm 750 \mathrm{~m}$.

\section{Discussion and conclusion}

The palaeogeomorphology of East China during the Late Mesozoic is a hot debated scientific problem, which directly influences the palaeogeography, palaeoclimate and paleontology of China and even that of the whole Asia. To date, various lines of investigation on East China have been taken from indirect proxy, such as petrology, palaeontology, and palaeoclimatology, but absence of analysis on paleoaltimeter, and this has led to controversy about the existence of East China plateau. Determining the absolute elevation in eastern China is necessary to understand how crustal processes contributed to creating the high topography of this part of China.

Our data indicate that the elevation of the sampling site in Inner Mongolai was near $5000 \mathrm{~m}$ above sea level when the lava flow was emplaced, implying that there used to be highland regions during early Cretaceous.

The implication of our data challenges the question about the boundary of the proposed eastern China plateau. Zhang et al. [44] have discussed the north boundary of the plateau in detail according to the distribution of the adakite rocks. They consider that the plateau boundary distributes along the Chifeng-Kaiyuan rift zone (Figure 1(a)), and the northern border of the plateau may have shifte to the south from late Jurassic to early Cretaceous. Our study area is located $200 \mathrm{~km}$ north of the plateau border suggested by Zhang et al. The $5000 \mathrm{~m}$ paleoelevation could suggest that our sampling area was part of the high plateau, or a separate high mountain $200 \mathrm{~km}$ north to the ancient high plateau border. Interestingly, there are reportes that early Cretaceous sediments from Changtu area of Liaoning Province and Xin Licheng area of Jilin Province contain large sum of ice raft depositions [45]. Because the paleolatitudes for these areas as well as for our sampling site were in the middle latitude zone $[46,47]$, these ice raft deposits should be formed in high altitude region. The existence of the early Cretaceous ice raft deposits in Liaoning and Jining and our high altitude paleoelevation data from Inner Mongolia suggest that the extent of the early Cretaceous high plateau in eastern China is much wider than what proposed by Zhang et al. [44].

As mentioned in the beginning, the collision between the NCB and SCB has played a central role in shaping up the eastern Asian continents. The amalgamation of the NCB and SCB took place in the Late Permian, with collision first occurring near the eastern end (in today's geographic coordinates: $30^{\circ} \mathrm{N}, 120^{\circ} \mathrm{E}$ ) of the Qinling Fold Belt and diachronously suturing from east to west due to a clockwise rotation of about $67^{\circ}$ of SCB relative to NCB [1]. By the Middle Jurassic, the Qinling Sea is almost completely closed. Consequently, North and South China were assem- bled by Middle Jurassic time.

We argue that with the cessation of the NCB-SCB subduction and associated magmatism in late Mesozoic and the closure of the PaleoTethys ocean in easternmost China due to collision, East China continent underwent dramatically reorganization. In particular, areas north of the NCB-SCB boundary, i.e. the outlined area in Figure 1(a), were under direct impact of collisional and rotational suturing. As there was no material escaped eastward, crustal thicking and uplifting must have been prevailing since Jurassic, building up topography in the region. Despite the uncertainties involved in dating tectonic events and paleoelevation determination, it seems clear that both the cessation of NCB-SCB collision and the existence of high elevation plateau in eastern China occurred in late Mesozic, suggesting some causal relationship.

To sum up, we conclude that there was a high plateau with elevation near $5000 \mathrm{~m}$ above sea level in Eastern China during the late Mesozoic. This vast ancient high plateau in eastern China was most likely a product of the collision of the North and South China blocks.

We thank the reviewers for helpful reviews and constructive suggestions. Wang Gang, Ou Lihua, Hui Bo, and Tang Yunfeng at Chengdu University of Technology are thanked for helping with fieldwork and offering useful discussions for this paper. This work was supported by the National Natural Science Foundation of China (40972084) and the US National Science Foundation (EAR-0911331).

1 Zhao X X, Coe R S. Paleomagnetic constrains on the collision and rotation of North and South China. Nature, 1987, 327: 141-144

2 Zhao X X, Coe R, Gilder S A, et al. Palaeomagnetic constraints on the palaeogeography of China: Implications for Gondwanaland. Aust J Earth Sci, 1996, 43: 643-672

3 Gilder S, Courtillot V. Timing of the North-south China collision from new Middle to Late Mesozoic paleomagnetic data from the North China Block. J Geophys Res, 1997, 102: 17713-17727

4 Maruyama S, Li J G, Seno T. Mesozoic and Cenozoic evolution of Asia. In: Ben-Avraham Z, ed. The Evolution of the Pacific Ocean Margins Oxford Monogr Geol Geophys, 1989, 8: 75-99

5 Lippert P C, Zhao X, Coe R S, et al. Palaeomagnetism and ${ }^{40} \mathrm{Ar} /{ }^{39} \mathrm{Ar}$ geochronology of upper Palaeogene volcanic rocks from Central Tibet: Implications for the Central Asia inclination anomaly, the palaeolatitude of Tibet and post-50 Ma shortening within Asia. Geophys J Int, 2011, 184: 131-161

6 Zhang Q, Qian Q, Wang E Q, et al. An East China Plateau in mid-late Yanshanian Period: Implication from Adakites (in Chinese). Chin J Geol, 2001, 36: 248-255

7 Wang P. Cenozoic deformation and the history of sea-land interactions in Asia. In: Clift P D, et al. eds. Continent-Ocean Interactions in the East Asian Marginal Seas. Am Geophys Union Geophys Monogr, 2004, 149: 1-22

8 Ren J S, Chen T Y, Niu B G, et al. Evolution of the Continental Lithosphere and Metallogeny in Eastern China and Adjacent Areas (in Chinese). Beijing: Science Press, 1990

9 Deng J F, Zhao H L, Mo X X, et al. Contiental Roots-Plume Tectonics of China: Key to the Continental Dynamics (in Chinese). Beijing: Geological Publishing House, 1996. 1-110

10 Wu G Y, Chen H J, Ma L, et al. Occurring of the East China Yanshanian Plateau and its inspiration to mineral and petroleum resources evaluation (in Chinese). Pet Geol Exp, 2002, 24: 3-12

$11 \mathrm{Li} \mathrm{X} \mathrm{H,} \mathrm{Xu} \mathrm{B} \mathrm{L,} \mathrm{Chen} \mathrm{Y} \mathrm{H,} \mathrm{et} \mathrm{al.} \mathrm{Clay} \mathrm{minerals} \mathrm{of} \mathrm{the} \mathrm{middle-late}$ 
Mesozoic mudrocks from North and Northeast China: Implications to paleoclimate and paleohghland (in Chinese). Acta Geol Sin, 2008, 82: 683-691

12 Zhang Q, Wang Y L, Jin W J, et al. Eastern China Plateau during the Late Mesozoic: Evidence, problems and implication (in Chinese). Geol Bull Chin, 2008, 27: 1404-1430

13 Ge X Y, Li X H, Chen Z G, et al. Geochemistry and petrogenesis of Jurassic high Sr/low Y granitoids in eastern China: Constranints on crustal thickness (in Chinese). Chin Sci Bull (Chin Ver), 2002, 47: 962-968

14 Chen B, Zhai M G, Shao J A. Petrogenesis and geological significance of the Mesozoic batholith in orthern segment of Taihang Mountain: Evidence from major and trace element geochemistry (in Chinese). Sci China Ser D, 2002, 32: 896-907

15 Zhang J. Discussion on adakite, its ore-bearing potential and some other related issues (in Chinese). Bull Mineral Pet Geochem, 2003, 22: 365-371

16 Small E E, Anderson R S. Geomorphically driven late Cenozoic rock uplift in the Sierra Nevada, California. Science, 1995, 270: 277-280

17 Coughline T J, O'Sullivan P B, Kohn P B, et al. Apatite fission-track thermochronology of the Sierras Pampeanas, central western Argentina: Implications for the mechanism of plateau uplift in the Andes. Geology, 1998, 26: 999-1102

18 Stockli D F, Farley K A, Dumitru T A. Calibration of the apatite (U-Th)/He thermochronometer on an exhumed fault block, White Mountains, California. Geology, 2000, 28: 983-986

19 Clark M K, House M A, Royden L H, et al. Late Cenozoic uplift of southern Tibet. Geology, 2005, 33: 525-528

20 Pares J M, Voo R V, Downs W R, et al. Northeastward growth and uplift of the Tibetan Plateau: Magnetostratigraphic insights from the Guide Basin. J Geophys Res-Solid Earth, 2003, 108: 2017

21 Forest C E, Molnar P, Emanuel K A. Paleoaltimetry from energy conservation principles. Nature, 1995, 374: 347-350

22 Forest C E, Wolfe J A, Molnar P, et al. Paleoaltimetry incorporating atmospheric physics and botanical estimates of paleoclimate. Geol Soc Am Bull, 1999, 111: 497-511

23 Spicer R A, Harris N B W, Widdowson M, et al. Constant elevation of southern Tibet over the past 15 million years. Nature, 2003, 421: 622-624

24 McElwain J C. Climate-independent paleoaltimetry using stomatal density in fossil leaves as a proxy for $\mathrm{CO}_{2}$ partial pressure. Geology, 2004, 32: 1017-1020

25 Chamberlain C P, Poage M A, Craw D, et al. Topographic development of the Southern Alps recorded by the isotopic composition of authigenic clay minerals, South Island, New Zealand. Chem Geol, 1999, 155: 279-294

26 Garzione C N, Dettman D L, Horton B K. Carbonate oxygen isotope paleoaltimetry: Evaluating the effect of diagenesis on paleoelevation estimates for the Tibetan Plateau. Palaeogeogr Palaeoclimatol Palaeoecol, 2004, 212: 119-140

27 Poage M A, Chamberlain C P. Emperical relationships between elevation and the stable isotope composition of precipitation and surface waters: Considerations for studies of paleoelevation studies. Am J Sci, 2001, 301: 1-15

28 Rowley D B, Pierrehumbert R T, Currie B S. A new approach to stable isotope-based paleoaltimetry: Implicationsn for paleoaltimetry and paleohypsometry of the High Himalaya since the Late Miocene.
Earth Planet Sci Lett, 2001, 188: 253-268

29 Currie B S, Rowley D B, Tabor N J. Middle Miocene paleoaltimetry of southern Tibet: Implications for the role of mantle thickening and delamination in the Himalayan orogen. Geology, 2005, 33: 181-184

30 Sahagian D L, Maus J E. Basalt vesicularity as a measure of atmospheric-pressure and palaeoelevation. Nature, 1994, 372: 449-451

31 Sahagian D L, Proussevitch A A, Carlson W D. Timing of Colorado Plateau uplift: Initial constraints from vesicular basalt-derived paleoelevations. Geology, 2002, 30: 807-810

32 Gregory K M. New prospects in old bubbles. Nature, 1994, 372: 407-408

33 Sahagian D L, Proussevitch A A, Carlson W D. Analysis of vesicular basalts and lava emplacement processes for application as a paleobarometer/paleoaltimeter. J Geol, 2002, 110: 671-685

34 Chen Z G, Zhang L C, Wu H Y, et al. Ar-Ar age, geochemistry and petrogenesis of Late Mesozoic volcanic rocks in the northern marginal region of Erlian basin, Inner Mongolia. Acta Pet Sin, 2009, 25: 297-310

35 Sahagian D, Proussevitch A. Paleoelevation measurement on the basis of vesicular basalts. Rev Mineral Geochem, 2007, 66: 195- 213

36 Sahagian D L, Anderson A T, Ward B. Bubble coalescence in basalt flows: Comparison of a numerical model with natural examples. J Volc Geotherm Res, 1989, 52: 49-56

37 Shin H, Lindquist W B, Sahagian D L, et al. Analysis of the vesicular structure of basalts. Comp Geosci, 2005, 31: 473-487

38 Toramaru A. Measurement of bubble size distributions in vesiculated rocks with implications for quantitative estimation of eruption processes. J Volc Geotherm Res, 1990, 43: 71-90

39 Sahagian D L, Proussevitch A A. 3D particle size distributions from 2D observations: Stereology for natural applications. J Volc Geotherm Res, 1998, 84: 173-196

40 Carlson W D. Three-dimensional imaging of earth and planetary materials. Earth Planet Sci Lett, 2006, 249: 133-147

41 Saltikov S A. The determination of the size distribution of particles in an opaque material from a measurement of the size distribution of their sections, of stereology. In: Proceedings of the Second International Congress for Stereology (Chicago, IL). New York: Springer-Verlag, 1967. 163-173

42 Underwood E E. Quantitative Stereology. New Jersey: AddisonWesley Publication, 1970. 23-133

43 Cruz-orive L M. Particle size-shape distributions: The general spheroid problem-II, Stochastic Model and Practical Guide. J Microsc, 1978, 112: 153

44 Zhang Q, Jin W J, Wang Y L, et al. Discussion of north boundary of the East China Plateau during late Mesozoic Era (in Chinese). Acta Pet Sin, 2007, 23: 689-700

45 Wang D P, Zhang L P, Frakes L A, et al. The discovery and significance of cretaceous ice-rafting deposits in Songliao Basin (in Chinese). J Changchun Univ Earth Sci, 1996, 26: 382-387

46 Zhu R X, Yang Z, Wu H, et al. Paleomagnetic constraints on the tectonic history of the major blocks of China during the Phanerozoic (in Chinese). Sci China Ser D-Earth Sci, 1998, 28, 1-16

47 Zhu R X, Shao J, Pan Y, et al. Paleomagnetic data from Early Cretaceous volcanic rocks of West Liaoning: Evidence for intracontinnental rotation (in Chinese). Chin Sci Bull (Chin Ver), 2002, 47: 1832-1837

Open Access This article is distributed under the terms of the Creative Commons Attribution License which permits any use, distribution, and reproduction in any medium, provided the original author(s) and source are credited. 